\title{
Endoscopic endonasal resection of cholesterol granuloma of the petrous apex
}

\author{
Volume 7 Issue 6 - 2017 \\ Juliano Colonetti,' Antonio Cesar de Mello \\ Mussi, ${ }^{2}$ Athos T Andrade de Athayde, ${ }^{2}$ Rafael \\ Pinz,' Gustavo Fabiano Nogueira,' Tiago \\ Scopel,' Rafael Pinz' \\ 'Otorhinolaryngologist, Brazil \\ ${ }^{2}$ Neurosurgeon, Brazil
}

\section{Introduction}

The petrous apex is one the most inacessible areastoreach in the skull base. The most commom type of lesion is cholesterol granuloma. The cause of the selesions still remain unknown and small lesions can be assymptomatic. Historically, surgery to the petrous Apex has been addressed via craniotomy and open microscopic anterior petrosectomy. ${ }^{2}$ The endoscopic endonasal approach offers a minimally invasive alternative to traditional surgical approaches in thetreatment of cholesterol granulomas of the petrous apex. The indications and applicability of endoscopic skull base surgery have rapidly advanced over the last decades from resection of benigns in onasal and pituitary tumours to the resection of lesions involving the cribiform plate to the upper cervical vertrebrae and extending to the petrous apex and infra temporal fossa. ${ }^{3}$ The purpose of this study is to describe how weper form the endocopic resection of cholesterol granuloma of the petrous apex using an unilateral approach. Recently then asosseptal flap has been used to permitlong-termpatency of drainage site. ${ }^{4}$

\section{Material and methods}

A 43years old man presented with 6month history of intermittent right hemicranial headache and ipsilateral conductive hearingloss. The patient had no historyof head trauma. The MRI demonstrated a large and expansile right petrous apex lesion hyper intense on both T1- and $\mathrm{T} 2$-weighted scans, without diffusion restriction or internal contrast enhancement. The CT scan showed and expansile and lyticlesion with surrounded bony erosion (Figures 1-4).

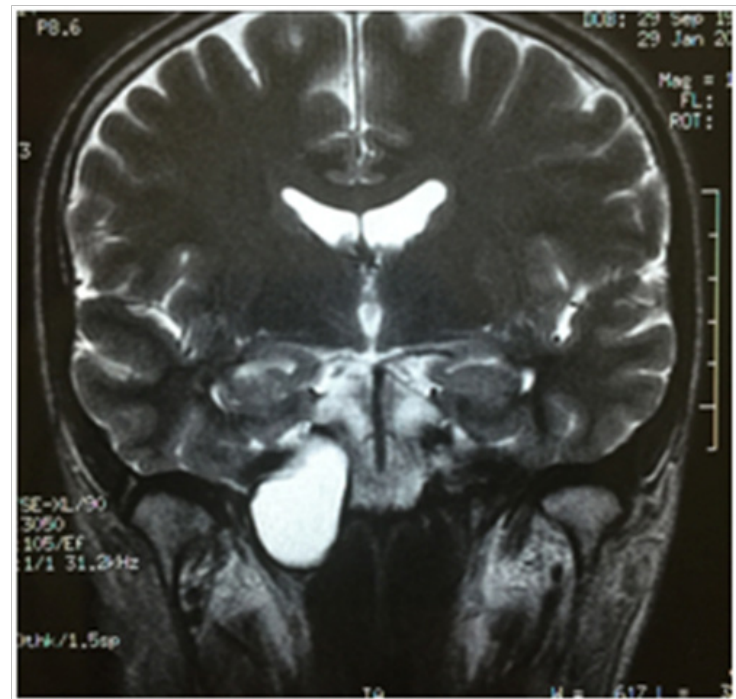

Figure I A large expansile lesion is noted in the right petrous apex, hyper intense on both $\mathrm{TI}$ - and T2-weighted scans, without diffusion restriction or internal contrast enhancement.

\section{Surgical technique}

A medial and unilateral trans sphenoidal trans clival
Correspondence: Juliano Colonetti, Otorhinolaryngologist, Brazil, Email julianocolonetti@hotmail.com

Received: November 07, 2017 | Published: June 23, 2017

approach with internal carotidartery lateralization combined with transpterygoidinfrapetrous approach was indicated because of the location of the lesion. Team surgery is mandatory when there is manipulation of the internal carotid artery and a risk of vascular injury. ${ }^{5}$ Bilateral sphenoidotomies provides more room for instrumentation and allow four-hand surgery by a team of surgeons an otolaryngology and a neurosurgeon, however unilateral sphenoidotomie approach can be a viable option and less invasive alternative. The sinonasal mucosa was de congested with topical epinephrine 1:2000. The partial inferior turbinectomy was done to facilitate the visualization. The maxillary antrostomy and ethmoid ectomy was performed the posterior wall ofth emaxillary sinus was removed exposing the contents of the pterygopalatine fossa. The sphenopalatine artery islocated, cauterized and transected to fully expose the base of the pterygoids. Medially, the palatovagin alartery, a terminal branch of th emaxillary artery was transected, and soft tissue of the pterygopalatine fossa were mobilized laterally to facilitate identification of the vidiannerve and artery. ${ }^{6}$ The pterygoid base wasdrilled out using a diamondburr $3.2 \mathrm{~mm}$, preserving the vidiannerve, untill the foramenlacerum soft tissue and anterior genu of the internal carotid artery were reached. ${ }^{6}$ The course and location of the ICA is confirmed with neuronavigation system. The bone between the horizontal petrous ICA and Eustachian tube wasdrilled out.

The eustachian tube is transected and the petrouscarotid canal is drilled out. The inferior surface of the PA is reached by drilling the bone between the horizontal segment of the petrousinternal carotidartery and the Eustachian tube, medial to the third division of the trigeminalnerve. ${ }^{5}$ The anterior and medial wall of the cystisopened and the cystcontents are removed with suctions, irrigation and curetes. The cholesterol granuloma was drained and the cystwall was marsupialized. A wide opened is mandatory. A silastic tube ( 6-mm pediatric endotraqueal T-tube) was placed in the new cavity to maintain patency during the healing process. 


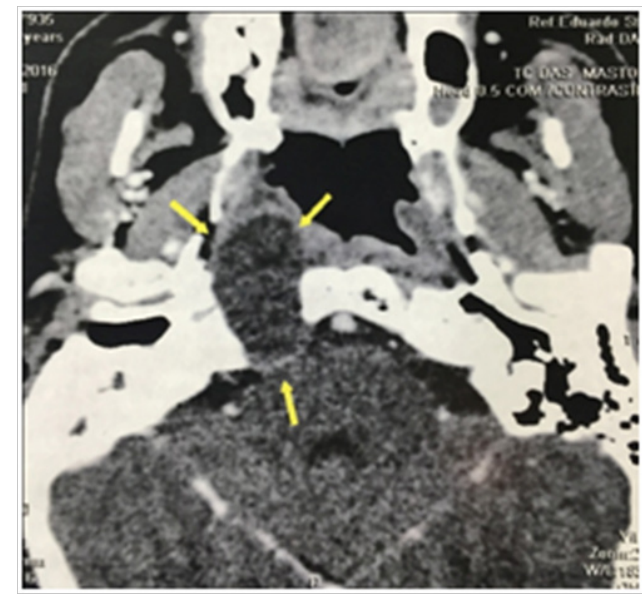

Figure 2 Preoperative axial contrast CT with a right expansile and lyticpetrous Apex lesion with bony erosion.

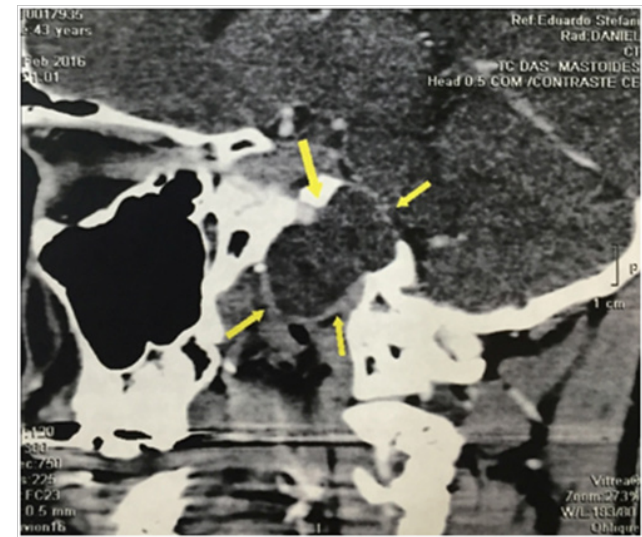

Figure 3 Preoperative sagital contrast CT Scan with a right expansile petrous apex lesion.

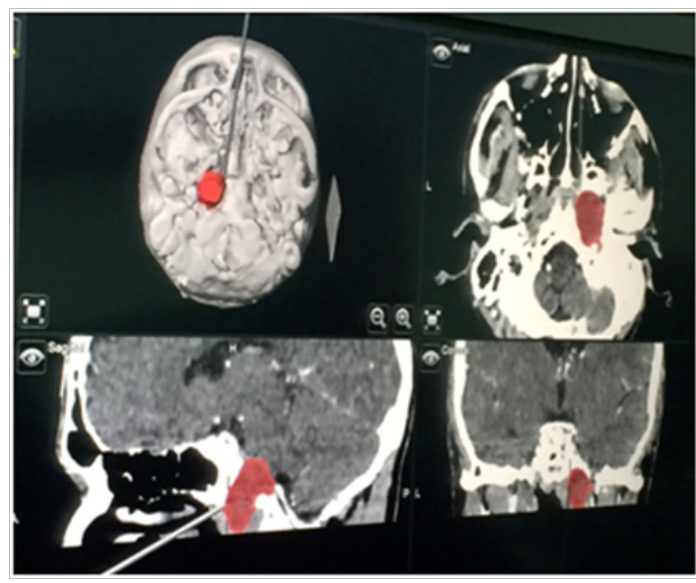

Figure 4 Image Guidance screen shot showing right petrous Apex lesion.

\section{Results}

The patient was discharged 5 days post operatively and at 2-month follow-up the silastic tube was removed under endoscopicvisualization at the office. The patient demonstrated significant improvement of pre-operatively symptons including resolution of headaches and improvement on his hearing loss.

\section{Discussion}

With the recent advances in minimally invasive surgery and intraoperatively image guidance systems, skull base endoscopy has led to new treatment options for petrous Apex lesions. ${ }^{8}$ Mostlesions are clinically silent until they adhere to cranial nerves, further this lesion can present with headaches, hearingloss, imbalance, facial weakness and/or diplopia. ${ }^{8}$ Principal treatment is surgical drainage and permanet aeration to prevent recurrence. ${ }^{5}$ The treatment strategies depend on the location and size of the lesion, based on drainage or complete excision of the capsule or cystdrainage. Recently, petrous apex cholesterol granuloma have been treated via end on as al transsphenoidal approach using silicone tube to create drainage, prevent route occlusion. Obstruction of the drainager out ehasled to problem swithrecurrence. ${ }^{9}$ The endoscopicendonasal approach provides a minimally invasive approach with wide operation field direct access to the midline and potential to extend approach to the superior and inferior PA.

Others advantages of the endoscopic endonasal approach include wide drainage window into the petrous apex connected with the natural corridor and sinonasalmucociliary system and postoperatively endoscopic surveillance in the office. ${ }^{10}$ The internal carotidartery is of critical importance for endoscopic endonasal approaches to the petrous apex, and it is useful to categorize these approaches based on the irrelationship to the internal carotidartery. ${ }^{5}$ The use of high speed drills with a diamond burr and image guidance allow sprecise removal of bone over the internal carotidartery and cyst wall. ${ }^{11}$

\section{Conclusion}

The endoscopic endonasal approach to petrous apexlesions is a safe and minimally invasive technique for adequately selected patients. This approach provide swide access to the cyst, out patient follow-up in office and if necessary, reopening with little morbidity in cases of recurrence. This approach is significantly less invasive than traditional transcranial procedures with overall reducedmorbidity, shortened procedure time, reduced hospital stay and better comestic results and lower recurrence rates.

\section{Acknowledgments}

None.

\section{Conflicts of interest}

Author declares there are no conflicts of interest.

\section{Funding}

None.

\section{References}

1. Lo WW, Solti-Bohman LG, Brackmann DE, et al. Cholesterol granuloma of the petrous Apex: CT diagnosis. Radiology. 1984;153(3):705-711.

2. Van Gompel JJ, Alikhani P, Tabor MH, et al. Anterior inferior petrosectomy: defining the role of endonasal endoscopic techniques for petrous Apex approaches. J Neurosurg. 2014;120(6): 1321-1325.

3. Chaaban MR, Chaudhry A, Riley KO, et al. Simultaneous Pericranial and Nasoseptal Flap Reconstruction of Anterior Skull Base defects following endoscopic-assisted craniofacial resection. Laryngoscope. 2013;123(10):2383-2386.

4. Karligkiotis A, BignamiM, Terranova $\mathrm{P}$, et al. Use of the pedicled nasoseptal flap in the endoscopic manegement of cholesterol granulomas of the petrous Apex. Int Forum Allergy Rhinology. 2015;8:747-753. 
5. Zanation AM, Snyderman CH, Carrau RL, et al. Endoscopic endonasalsurgery for petrous Apex lesions. Laryngoscope. 2009;119(1):19-25.

6. Prevedello DM, Pinheiro Neto CD, Fernandez Miranda JC, et al. Vidiannerve transposition for endoscopic endonasal middle fossa approaches. Neurosurgery. 2010;67(2 Supple ):478-484.

7. Griffith Aj, Terell JE. Trans sphenoid endoscopic manaegement of petrous Apex cholesterol granuloma. Otolaryngology Head Neck Surgery. 1996;114: 91-94.

8. Isaacson B. Cholesterol granuloma and othe rpetrous Apex lesions. Otolaryngol Clin North Am. 2015;48(2):361-373.
9. Shibao S, Toda M, Tomita T, et al. Petrous Apex cholesterol granuloma: importance of pediclednasoseptal flap in addition to silicone T-tube for prevention of occlusion of drainage route in transsphenoidal approach a technical note. Neurol Med Chir (Tokyo). 2015;55(4):351-355.

10. ChatrathP, Nouraei SA, De Cordova J, et al. Endonasal endoscopic approach tothepetrous Apex: animage-guided quantitative anatomicalstudy. Clinical Otolaryngology. 2007;32(4):255-260.

11. Scopel TF1, Fernandez Miranda JC, Pinheiro-Neto CD, et al. Petrous Apex Cholesterol Granulomas: Endonasal versus Infracochlear Approach. Laryngoscope. 2012;122(4):751-761. 